\title{
Why Should you Choose to Publish your Article in International Journal of Pharmacology, Phytochemistry and Ethnomedicine?
}

\author{
Mohamed Nadjib BOUKHATEM ${ }^{1,2^{*}}$ \\ ${ }^{1}$ Département de Biologie et Physiologie Cellulaire, Faculté des Sciences de la Nature et de la Vie, \\ Université - Saad Dahleb - Blida 1, Blida, Algeria \\ ${ }^{2}$ Laboratoire Ethnobotanique et Substances Naturelles, Département des Sciences Naturelles, \\ Ecole Normale Supérieure de Kouba, Alger, Algeria \\ ${ }^{*}$ Corresponding Author: Dr. Boukhatem Mohamed Nadjib \\ Editor in Chief of International Journal of Pharmacology, Phytochemistry and Ethnomedicine. \\ Web site: https://www.scipress.com/IJPPE/details ; Mail: ijppe@scipress.com;
}

Phone: +213.559146610

\begin{abstract}
Keywords: International Journal of Pharmacology, Phytochemistry and Ethnomedicine, SciPress Publishing House, Publication, Submission, Open Access.
\end{abstract}

\begin{abstract}
Choosing a scientific journal for publication of research article or review paper is a universal problem faced by all scientists and $\mathrm{PhD}$ students after finishing his/her scientific research. Generally, the authors of pharmaceutical and medical journals are neither paid nor do they expect any financial recompense for their publication. What then is the motivating power behind researcher's enthusiasm to publish their paper? It is possibly, the pleasure and gratification of being an element of the progression of pharmaceutical sciences and medicine through research and successive publication. Nevertheless, the true worth of a research deception is in its citation by other scientists after publication. Thus, the paper should be read by as several researchers as possible. The aim of this editorial paper is to talk about the significant reasons that the scientist and author should consider and judge while choosing International Journal of Pharmacology, Phytochemistry and Ethnomedicine (IJPPE) for submission and publication, so as to improve and increase the probability of acceptance to add value to their research and study, and most of all guarantee an extensive distribution and readership. Then why not submit and publish your best scientific articles in IJPPE and add value to your research and paper.
\end{abstract}

\section{Introduction}

Pharmacologists, Doctors, Biologists, Chemists, Nutritionists, young researchers and PhD scholars spend a lot of time conversing and discussing over the most suitable scientific journal to submit their most recent review or research papers. Authors occasionally have trouble distinguishing between the most important scientific journals, and are anxious that they will be asked to pay great page fees and charges.

An additional concern is that their research papers might be tied up for several days or weeks in the review procedure and finally not accepted or rejected. Furthermore, there are novel scientific journals springing up with several of them offering large benefits, such as free Open Access and fast online publication. Nevertheless, such predatory journals frequently require visibility and a recognized impact factor, so a paper published in one of these predatory journals might not get discerned or count toward promotion.

\section{Submit Your Scientific Article to IJPPE and Give It the international Impact It merits}

As the Editor-in-Chief, I can affirm with some assurance that the International Journal of Pharmacology, Phytochemistry and Ethnomedicine (IJPPE) was produced in order to offer a nonbias avenue for publication of ideas, original research, views and reviews to a broad-ranging readership. We trust that anyone with an interest in Pharmaceutical Sciences, Phytomedicine and Medicinal Chemistry will browse through our journal and discover something of interest, significance and value. 
IJPPE was created to enhance the occasions for research results focusing on Pharmaceutical Sciences and Human Health issues in all nations to be seen along with additional scientific journals. Since its launching in 2015, IJPPE has progressed gradually and developed.

The aim of the IJPPE is to offer and provide a platform for scientists, researchers and academicians all over the world to promote, share and discuss various new issues and developments in both the areas of Phytomedicine and Pharmaceutical Technology.

The scope of the IJPPE includes the branches like Medicinal Chemistry, Ethnopharmacology, Phytomedicine, Phytochemistry, Medicinal Food, Ethnobotany, Functional Food, Food Chemistry, Nutraceuticals, Analytical Chemistry, Biochemistry, Bioinformatics, Biopharmaceutics, Biotechnology, Clinical Research, Drug discovery, Microbiology, Novel Nutrition, Toxicology, Pharmaceutics, Pharmacognosy, Pharmacology, Pharmacy Practice, Analytical R\&D in Pharma.

Furthermore, Research papers and Reviews in IJPPE are read and cited by scientists from all countries of the world. This gives evidence to its success and achievement in realizing its objective of spreading the research results and data of its authors worldwide. Significantly, and as a strategy, IJPPE Editor in Chief work directly and honestly with authors to assist them get their papers accepted and online published in IJPPE.

\section{Benefits of publishing with IJPPE}

In opposition to these apprehensions about new on-line predatory journals and the older, established journals, the IJPPE is value considering for the following reasons:

\section{- Online Submission - Reducing Publication Times}

Peer-review process gives importance and worth to the submitted papers [1]. "Science needs that publications be correctly and appropriately vetted and results reasonably presented [2]. Thus, authors wish to get their papers published in peer-reviewed publications.

IJPPE has adopted SciPress online submission system, which allows authors to submit manuscripts via the Web. This system speeds up the submission and refereeing process, and allows authors to see the status of their articles online.

IJPPE use the Editor Tool for managing the submission and peer-review process. Editor Tool allows authors to submit their papers, reviewers - to review the manuscripts and editors - to handle the peer-review process online. Editor Tool offers a variety of possibilities to the Authors, as well as:

- IJPPE provides facility for online submission from www.scipress.com

- IJPPE provides user-friendly interface

- IJPPE system allows simply upload manuscript

- Authors can online monitoring status of their manuscript

- Instantly see review and editor's comments

- Easy upload revised manuscrit

- Direct communication with the Editor in Chief

- Find all notification regarding their manuscript

- The whole review process is automatic and web-based, in consequence resulting into a quicker decision on papers.

- The regular 'submission-decision' time has become less than 6-8 weeks since inauguration of this system.

\section{- No Page Charges}

IJPPE does not have publication charges or fees, in difference with other most important scientific journals. Publication of your scientific papers in IJPPE is FREE of charge if submitted before September 30, 2016. There are no any hidden article processing fees. Color illustrations and figures are free in the on-line version of the research paper.

\section{- Rapid Peer-Review Process}

Reviewers and referees play an important responsibility in scholarly publishing. Fundamentally the peer review process for IJPPE publication is a quality control and research validation method. It is a procedure of expert assessment of academic research aimed at guarantying 
high quality of published scientific articles. However, Reviewers do not decide on accepting or rejecting papers, they only recommend a decision on this matter to the IJPPE Editor in Chief.

Once the manuscript has been submitted, IJPPE has a rapid and quick first editorial review process (Figure 1). The Editor in Chief screens the article for suitability to the journal and decides whether to send it for full peer review. The IJPPE Editor checks whether the article meets all basic requirements for papers submitted to the journal. Each manuscript undergoes a double-blind review process before a decision on acceptance to publication is made.

Manuscripts not suitable for the IJPPE are not accepted and returned without peer review, saving author precious time. Else, the paper, which is not matching the criteria, will be rejected.

On completion of the peer review, all the Reviewers send their detailed Reviewer's reports with comments and recommendations on the manuscript. The Reviewer's report will help the Editor decide whether or not to publish the article.

As a final point, the journal Editors or the Editorial board learn and study the peer reviewers' reports and make an ultimate decision. The regular time from the date of submission to the initial editorial decision is 6 to 8 weeks. We are strongly committed to reviewing your article without delay_ and the timeliest research qualifies for accelerated review.

\section{- Rigorous Review and Professional handling}

We have a team of qualified editors committed to handling your submitted manuscript professionally and quite, and providing you with an exceptional author service.

All the papers get meticulous and beneficial peer review overseen by working researchers and scientists who are world-class specialists and expert in their own disciplines. Our Editorial Board members are made up of eminent and reputed researchers and scientists in related fields.

IJPPE Publication has support of over 50 excellent reviewers from various fields (Pharmacology, Phytochemistry, Medicine, Biology, Biochemistry, Nutrition, Endocrinology, Toxicology and Chemistry), this ensures we complete the review process in shortest span of period. This, joint with a well-organized electronic submission and electronic refereeing system, makes submitting and publishing with IJPPE of perfect.

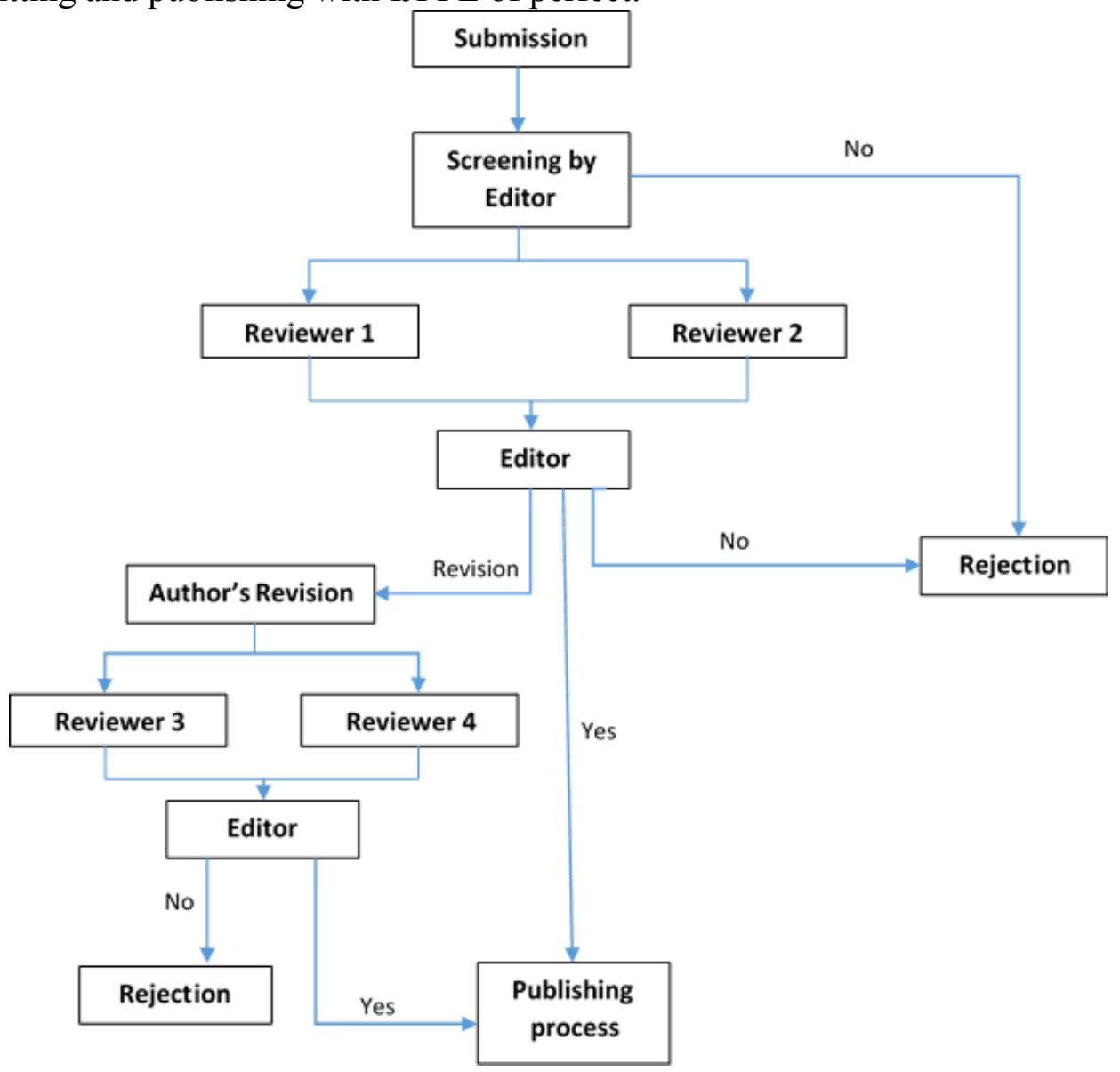

Figure 1. The Peer-review process in IJPPE from submission to final decision. 


\section{- Free Access and Full text visibility}

IJPPE is fully Open Access journal, covering all areas of pharmaceutical sciences, phytochemistry, Ethnopharmacology, Nutrition, Medicinal Chemistry, Drug design, Biological sciences, Medicine and Toxicology. IJPPE is committed to the Open Access model of publishing. This ensures free web access to the results of research articles and total visibility for published papers.

All the paper IJPPE publish is open access, meaning it is free to access from anyplace in the world. It can also be reproduced and re-used for any reason or purpose, as long as it is attributed, enhancing the value and utility of your research. As well as being published on IJPPE website, your paper is also available on Google Scholar and all other major full-text repositories.

Further, Authors can make their final version of the article freely available on their institutional website instantly upon acceptance of the paper for publication. Hence, Free online papers have been reported to be cited more frequently [3-5].

Finally, researchers from the developing world will not be handicapped due to the poor economic state of the country.

In the other hand, the complete content published with SciPress Publishing House is freely accessible online immediately upon publication. SciPress Publishing House views open access to research as necessary and vital in order to guarantee the fast and professional communication of research findings.

\section{- Authors retain rights}

Authors keep numerous of the rights to their articles after online publication, such as freedom to dispense copies to researchers, colleagues and $\mathrm{PhD}$. students as part of teaching.

Authors publishing with IJPPE retain the copyright to their work, licensing it under a Creative Commons license. IJPPE (SciPress Publishing House) applies the Creative Commons Attribution (CC BY 4.0) license to works we publish. This license was developed to facilitate open access namely, free immediate access to, and unrestricted reuse of, original works of all types. Under this license, authors agree to make articles legally available for reuse, without permission or fees, for virtually any purpose. Anyone may copy, distribute or reuse these articles, as long as the author and original source are properly cited.

\section{- Authors are satisfied}

Authors publishing in IJPPE report a total satisfaction with the journal. For all of these reasons and more, IJPPE is an excellent scientific journal in which to publish your most excellent articles in the field of pharmaceutical sciences and medicinal chemistry, principally those papers with significance to Pharmacognosy and Phytomedicine.

\section{- High visibility}

IJPPE have an increased visibility through different platforms. IJPPE is freely and permanently available online at SciPress website and are listed in the Directory of Open Access Journals (DOAJ), increasing visibility and discoverability.

IJPPE is indexed with a large number of bibliographic databases including: Google Scholar, Open J-Gate, Directory of Open Access scholarly Resources (ROAD), Elektronische Zeitschriftenbibliothek (EZB), AcademicKeys.

As soon as the issues are ready we provide the citations, thus ensuring that the abstracts are available immediately from Google Scholar.

IJPPE extensively promote your scientific research, leading to widespread exposure the scientific and general press, giving highest visibility and coverage for your papers and making them simple to download and cite. We also promote and support our journal at several scientific events and conferences throughout the year. We strive to promote your research to a wide audience. Increase the visibility of your article by publishing with IJPPE.

\section{- An important scientific legacy}

IJPPE publication persists to innovate in the publishing process, developing technology and regularly reviewing our policies in order to preserve our assignment of delivering the best quality service to readers and authors. 


\section{- High Quality and Rapid production process}

IJPPE is committed to preserving high quality standards. When you publish with IJPPE your article is in the company of other high-quality research. Authors who choose to submit and publish in the IJPPE journal can be guaranteed that its staff's publishing, editorial board and production skills are devoted to preserving the maximum promising standards and quality.

Once papers are accepted, they go through a rapid production process and soon appear online. The whole quality and value of presentation of final articles are high.

\section{- Regular free e-mail alerts}

Content published in IJPPE has the potential to reach scientists around the world who have signed up for Newsletter, ensuring additional exposure to authors.

\section{Submission process}

Discover the benefits of publishing your research with IJPPE and submit your article today. If you already have an account with us, just login and submit your paper.

In case you have never published with us and have no SciPress account, please register first to submit your paper. After login you should go through the following steps:

- Choose IJPPE journal, in which you want to publish your paper.

- Pick out a class of the scientific research in the item "Edit paper", point a paper in Doc and Pdf formats and press the button "Upload".

- Add your "Paper Title" and "Abstract".

- Add all authors of the paper in the item "Edit authors".

- Check the keywords list or add new keywords in the item "Edit keywords".

- Read the Copyright Agreement in the item "Copyright", select the type of the work, confirm to sign the Copyright Agreement and press the button "Submit".

- Point all necessary items in the section "Checklist". It is possible to submit the Checklist only after you fill in all the required information about author's paper during the previous steps.

- Finally you need to put the necessary marks in the Checklist and confirm it by pressing the "Submit" button thereby finalizing the submission of your paper.

\section{Society Publisher: SciPress}

IJPPE is published by SciPress which is a scientific publishing house located in Zurich (Switzerland), with a strong focus on theoretical and applied physical sciences, engineering, earth sciences, social sciences and humanities. The cutting-edge technology helps our authors worldwide to publish results of their research and development fast and easy.

Today SciPress publishes already 9 journals and is ready to acquire more periodicals with Open Access approach in all fields of scientific literature. The ambitious goal is to bring the journals from smaller publishers to a high scholarly level by utilizing our experience and knowledge of the global STEM market.

All over the world SciPress provides web open access to databases of scientific research in various fields, written as high quality stand-alone papers or compiled as special topic volumes, proceedings of international conferences and monographs.

In the time of Knowledge Economy, SciPress developed a user and scientist friendly web interface, providing simple yet efficient and easy-to-use system for uploading and reviewing papers. To keep up with the times, the company is always looking for new solutions to give the best possible support and service to its authors. By implementing users' ideas, SciPress integrates advanced algorithms in its ePlatform to deliver a smarter user experience to help authors improve and develop their scientific ideas and increase their research visibility.

As a Society publisher, Scipress Publishing House is devoted to advancing science and helping the needs of the scientific and academic communities. It's what drives us to present the highest-quality peer-review, technical editing, and production services for your manuscript. 
Scipress Publishing House is an active, inventive, ingenious company, devoted to publishing high quality, peer-reviewed research and review paper. Scipress Publishing House uses revolutionary and new technologies, modern formats and world class production to offer first-class information for scientific community in the private and public divisions, educators and government agencies.

\section{We are waiting for your submissions}

IJPPE scores fairly well in all the pointers mentioned above. Then why not publish your best research papers in IJPPE and add value to your research and paper.

We work for the quality and do our best to make our IJPPE match the high rank of scientific success and the world scientific community interests.

Over 40 authors have chosen to publish with International Journal of Pharmacology, Phytochemistry and Ethnomedicine. Try it yourself and discover why.

Our editorial board members are constantly prepared to support you with particular wishes. Please do not hesitate to contact us for any questions regarding this journal or other demand you have.

We are especially looking for outstanding and excellent original research articles and review papers on the most exciting new topics.

\section{References}

[1] B.K. Nayak, R. Maniar, S. Moreker, The agony and the ecstasy of the peer-review process, Ind. J. Ophthalmol. 53 (2005) 153-155.

[2] V.B. Shidham, A. Cafaro, B.F. Atkinson, Cyto Journal joins "open access" philosophy, Cyto. J. 1 (2004) 1.

[3] V.B. Shidham, L. Sandweiss, B.F. Atkinson, First CytoJournal Peer-Reviewer's Retreat in 2006 - Open access, peer-review, and impact factor, Cyto. J. 3 (2006) 5.

[4] A. Bredan, S. Benamer, O. Bakoush, Why should you choose to publish in the Libyan Journal of Medicine?, Libyan. J. Med. 11 (2016) 32756.

[5] K. Antelman, Do open-access articles have a greater research impact?, Coll. Res. Libr. 65 (2004) 372-382. 